\title{
COMMENT
}

\section{Maternal and infant vitamin B12 status and development}

\author{
A. David Smith ${ }^{1}$ \\ Pediatric Research (2018) 84:591-592; https://doi.org/10.1038/s41390-018-0110-0
}

Stunting affected at least 165 million children in the world in 2011 and was found in $7 \%$ of children in high-income countries and in $28 \%$ of children in low- to middle-income countries. ${ }^{1}$ Although the causes of stunting are many, maternal nutrition is one of the causes that can be modified by interventions. ${ }^{2}$ It is therefore of great interest that the maternal status of a micronutrient, vitamin B12, assessed when the infant is being breastfed, is related to the height of the child several years later. ${ }^{3}$ In this study on women and children in Nepal, blood samples from mothers and infants were taken when the infants were on average 7 months old and were being breastfed. The plasma total vitamin B12 of both mother and infant were each associated with the height of the child aged $5 \mathrm{y}$. Furthermore, the vitamin B12 intake of the mother while breastfeeding was also related to the child's height at age $5 \mathrm{y}$. The mean maternal daily intake of B12 was $0.8 \mu \mathrm{g}$, well below the RDA of $2.6 \mu \mathrm{g}$ but only $5 \%$ of mothers were B12 deficient by the usual definition $(<148 \mathrm{pmol} / \mathrm{L}$ in plasma). It is striking that the maternal B12 status over the whole range of observed plasma values was linearly related to the child's height at age $5 \mathrm{y}$. Likewise, the association between B12 intake and height was approximately linear over the whole range of intake. Each increment in maternal B12 intake of $1 \mu \mathrm{g}$ was associated with an increase in the child's height of $1.7 \mathrm{~cm}$. The authors stated that their results "do not suggest any cutoffs indicating when intake or status was adequate and indicate that most of the participants would benefit from increasing their intake of vitamin B12". It has been pointed out previously that in general several adverse outcomes are related to B12 status in the low-normal range but above the traditional cutoff value for deficiency. ${ }^{4,5}$ Does this mean that we should ensure that maternal B12 status is well above 148 $\mathrm{pmol} / \mathrm{L}$ in mothers?

The vitamin B12 status in pregnant woman world-wide is poor: a survey of 11 cohorts including 11,381 women showed a deficiency $(<148 \mathrm{pmol} / \mathrm{L})$ rate of $27.5 \%$ and an insufficiency $(<300 \mathrm{pmol} / \mathrm{L})$ rate of $60 \% .^{5}$ A large systematic review including 57 cohorts of $>30,000$ pregnant women found deficiency rates of $21 \%, 19 \%$, and $29 \%$ in the first, second, and third trimesters, respectively. ${ }^{6}$ There is evidence that poor B12 status is harmful for the health of the pregnant woman. For example, it increases the risk of gestational diabetes, obesity, and anemia not only in low- and middle-income countries and in countries with a high proportion of vegetarians, but also in high-income countries. ' Low pregnancy B12 status across the whole normal range increases the risk of preterm birth. ${ }^{8}$ Furthermore, B12 interacts with other nutrients. In pregnant women with low B12 status and high folate status there is an increased risk of gestational diabetes, ${ }^{9}$ of small for gestational age babies ${ }^{10}$ and of insulin resistance and obesity in the children aged $6 \mathrm{y} .^{11}$
Maternal B12 status is an important determinant of the B12 status of the infant during gestation and also later: infants that are breastfed have markedly lower B12 status than nonbreastfed infants (reviewed in refs. ${ }^{5,12,13}$ ). A low B12 status even occurs in infants that are only intermittently breastfed compared with those not breastfed. ${ }^{14}$ A key question is whether the low infant B12 status in breastfeeding is solely explained by the low content in breast milk ${ }^{15}$ or whether breast milk causes a change in B12 homeostasis in the infant.

Low B12 status in the mother has been associated with several adverse outcomes in the child. ${ }^{5,13,16,17}$ It is not often recognized that low-normal periconceptual B12 status leads to an increased risk of neural tube defects. ${ }^{18-20}$ In countries that have fortified flour with folic acid, low B12 status is a likely cause of some of the residual neural tube defects. ${ }^{21}$ In countries like India where the prevalence of neural tube defects ${ }^{22}$ is very high (4.5/1000 births) and where B12 status is very poor, but folate status is quite good, low B12 may be an important cause of neural tube defects.

Infants born from mothers whose B12 status is marginal are at risk of developmental impairments if they are breastfed. In one study, children at age $9 \mathrm{y}$ of mothers who had poor B12 status in pregnancy performed worse on some cognitive tests than children of mothers with good B12 status. ${ }^{23}$ Case series reported from both high-income and low-income countries ${ }^{24,25}$ describe a similar set of serious symptoms related to inadequate B12 in breastfed infants, including: failure to thrive, hypotonia, irritability, developmental delay, epilepsy, movement disorder, brain atrophy. ${ }^{5,26,27}$ It is imperative to treat the child with vitamin B12 as soon as possible. Many of these symptoms can then be reversed, even the brain atrophy, but long-term cognitive deficits may still occur.

Some valuable observational studies have supported the view that B12 status in the mother and in the infant is important for future child development. Maternal B12 status at 28 weeks' gestation was positively associated with the child's mental and social development quotients at 2 years. ${ }^{28}$ Children $12-18$ months old in North India were found to show better increments in mental development index scores the higher their plasma B12 level measured 4 months previously. ${ }^{29}$ It is noteworthy that in the latter study the association of B12 with cognition was approximately linear over the whole normal range of B12. In Nepal, the status of plasma markers of B12 in infants at 7 months was significantly related to visuospatial abilities and social perception at the age of $5 \mathrm{y} .{ }^{30}$ The authors concluded: "The long-term effects of poor vitamin B-12 status in infancy need further investigation in randomized controlled trials." Although there have been few clinical trials in this area (reviewed in ref. ${ }^{5}$ ), a provisional conclusion is that long-term supplementation with B12 at low doses may be beneficial in those children who are stunted or have

'Department of Pharmacology, University of Oxford, Oxford, UK

Correspondence: A. David Smith (david.smith@pharm.ox.ac.uk)

Published online: 17 July 2018 
poor B12 status at the start, giving increased growth and improved motor performance and problem-solving skills. ${ }^{31}$

\section{WHAT SHOULD BE DONE?}

In the absence of definitive clinical trials, which must be done but that would be very challenging to perform, what is the clinician to do? First of all, be aware that vitamin B12 status is important in both mother and child and that the desirable level is considerably above the traditional cutoff value. We have suggested that a plasma or serum concentration of about $300 \mathrm{pmol} / \mathrm{L}$ or above represents B12 sufficiency., ${ }^{4,5}$ Second, consider administering oral supplements of vitamin B12 to pregnant and lactating women whose B12 status is marginal. A trial in India showed that $50 \mu \mathrm{g}$ methylcobalamin per day from 14 weeks gestation to 6 weeks postpartum led to increased maternal and infant plasma B12 levels and also to increased breast milk levels. ${ }^{32}$ On the basis of current knowledge, these consequences may well be beneficial for both mother and child.

\section{REFERENCES}

1. Black, R. E. et al. Maternal and child undernutrition and overweight in low-income and middle-income countries. Lancet 382, 427-451 (2013).

2. Bhutta, Z. A. et al. Evidence-based interventions for improvement of maternal and child nutrition: what can be done and at what cost? Lancet 382, 452-477 (2013).

3. Strand, T. A., et al. Maternal and infant vitamin B12 status during infancy predict linear growth at 5 years. Pediatr Res in press (2018). https://doi.org/10.1038/ s41390-018-0072-2.

4. Smith, A. D. \& Refsum, H. Do we need to reconsider the desirable blood level of vitamin B12? J. Intern. Med. 271, 179-182 (2012).

5. Smith, A. D., Warren, M. J. \& Refsum, H. Vitamin B12. Adv. Food Nutr. Res. 83, 215-279 (2018).

6. Sukumar, N. et al. Prevalence of vitamin B-12 insufficiency during pregnancy and its effect on offspring birth weight: a systematic review and meta-analysis. Am. J. Clin. Nutr. 103, 1232-1251 (2016).

7. Sukumar, N. et al. Vitamin B12 status among pregnant women in the UK and its association with obesity and gestational diabetes. Nutrients 8, 768 (2016).

8. Rogne, T. et al. 2017 Associations of maternal vitamin B12 concentration in pregnancy with the risks of preterm birth and low birth weight: a systematic review and meta-analysis of individual participant data. Am. J. Epidemiol. 185 212-223 (2017)

9. Lai, J. S. et al. High folate and low vitamin B12 status during pregnancy is associated with gestational diabetes mellitus. Clin. Nutr. 37, 940-947 (2018).

10. Dwarkanath, P. et al. High folate and low vitamin B-12 intakes during pregnancy are associated with small-for-gestational age infants in South Indian women: a prospective observational cohort study. Am. J. Clin. Nutr. 98, 1450-1458 (2013).

11. Yajnik, C. S. et al. Vitamin B12 and folate concentrations during pregnancy and insulin resistance in the offspring: the Pune Maternal Nutrition Study. Diabetologia 51, 29-38 (2008).

12. Bjorke-Monsen, A. L. \& Ueland, P. M. Cobalamin status in children. J. Inherit. Metab. Dis. 34, 111-119 (2011).
13. Obeid, R., Murphy, M., Sole-Navais, P. \& Yajnik, C. Cobalamin status from pregnancy to early childhood: lessons from global experience. Adv. Nutr. 8, 971-979 (2017).

14. Hay, G., Johnston, C., Whitelaw, A., Trygg, K. \& Refsum, H. Folate and cobalamin status in relation to breastfeeding and weaning in healthy infants. Am. J. Clin. Nutr. 88, 105-114 (2008).

15. Dror, D. K. \& Allen, L. H. Vitamin B-12 in human milk: a systematic review. Adv. Nutr. 9, 358S-366S (2018)

16. Finkelstein, J. L., Layden, A. J. \& Stover, P. J. Vitamin B-12 and perinatal health. Adv. Nutr. 6, 552-563 (2015).

17. Venkatramanan, S., Armata, I. E., Strupp, B. J. \& Finkelstein, J. L. Vitamin B-12 and cognition in children. Adv. Nutr. 7, 879-888 (2016).

18. Molloy, A. M. et al. Maternal vitamin B12 status and risk of neural tube defects in a population with high neural tube defect prevalence and no folic acid fortification. Pediatrics 123, 917-923 (2009).

19. Wang, Z. P., Shang, X. X. \& Zhao, Z. T. Low maternal vitamin B(12) is a risk factor for neural tube defects: a meta-analysis. J. Matern. Fetal Neonatal Med. 25, 389-394 (2012).

20. Tang, K. F., Li, Y. L. \& Wang, H. Y. Quantitative assessment of maternal biomarkers related to one-carbon metabolism and neural tube defects. Sci. Rep. 5, 8510 (2015).

21. Thompson, M. D., Cole, D. E. \& Ray, J. G. Vitamin B-12 and neural tube defects: the Canadian experience. Am. J. Clin. Nutr. 89(Suppl), 697S-701S (2009).

22. Allagh, K. P. et al. Birth prevalence of neural tube defects and orofacial clefts in India: a systematic review and meta-analysis. PLOS ONE 10, e0118961 (2015).

23. Bhate, V. et al. Vitamin B12 status of pregnant Indian women and cognitive function in their 9-year-old children. Food Nutr. Bull. 29, 249-254 (2008).

24. Honzik, T. et al. Clinical presentation and metabolic consequences in 40 breastfed infants with nutritional vitamin B12 deficiency--what have we learned? Eur. J. Paediatr. Neurol. 14, 488-495 (2010).

25. Goraya, J. S., Kaur, S. \& Mehra, B. Neurology of nutritional vitamin B12 deficiency in infants: case series from India and literature review. J. Child Neurol. 30, 1831-1837 (2015)

26. Dror, D. K. \& Allen, L. H. Effect of vitamin B12 deficiency on neurodevelopment in infants: current knowledge and possible mechanisms. Nutr. Rev. 66, 250-255 (2008).

27. Demir, N., Koc, A., Ustyol, L., Peker, E. \& Abuhandan, M. Clinical and neurological findings of severe vitamin B deficiency in infancy and importance of early diagnosis and treatment. J. Paediatr. Child Health 48, 820-840 (2013).

28. Bhate, V. K. et al. Vitamin B12 and folate during pregnancy and offspring motor, mental and social development at 2 years of age. J. Dev. Orig. Health Dis. 3, 123-130 (2012).

29. Strand, T. A. et al. Cobalamin and folate status predicts mental development scores in North Indian children 12-18 mo of age. Am. J. Clin. Nutr. 97, 310-317 (2013).

30. Kvestad, I. et al. Vitamin B-12 status in infancy is positively associated with development and cognitive functioning 5 y later in Nepalese children. Am. J. Clin. Nutr. 105, 1122-1131 (2017).

31. Kvestad, I. et al. Vitamin B12 and folic acid improve gross motor and problemsolving skills in young North Indian children: A randomized placebo-controlled trial. PLOS ONE 10, e0129915 (2015).

32. Duggan, C. et al. Vitamin B-12 supplementation during pregnancy and early lactation increases maternal, breast milk, and infant measures of vitamin B-12 status. J. Nutr. 144, 758-764 (2014). 